This item was submitted to Loughborough's Research Repository by the author.

Items in Figshare are protected by copyright, with all rights reserved, unless otherwise indicated.

\title{
Flexible, all metal-oxide capacitors for printed electronics
}

PLEASE CITE THE PUBLISHED VERSION

https://doi.org/10.1109/NMDC.2018.8605872

PUBLISHER

(c) IEEE

VERSION

AM (Accepted Manuscript)

LICENCE

CC BY-NC-ND 4.0

REPOSITORY RECORD

McGhee, Jack R., Ryan Middlemiss, Darren J. Southee, K.G.U. Wijayantha, and Peter S.A Evans. 2019. "Flexible, All Metal-oxide Capacitors for Printed Electronics". figshare. https://hdl.handle.net/2134/36661. 


\section{Flexible, All Metal-Oxide Capacitors for Printed Electronics}

\author{
J. R. McGhee \\ Loughborough University Design School \\ Loughborough University \\ Loughborough, United Kingdom \\ j.mcghee@lboro.ac.uk \\ R. B. Middlemiss \\ Loughborough University Design School \\ Loughborough University \\ Loughborough, United Kingdom \\ r.middlemiss@lboro.ac.uk
}

\author{
D. J. Southee \\ Loughborough University Design School \\ Loughborough University \\ Loughborough, United Kingdom \\ d.j.southee@lboro.ac.uk \\ K. G. U. Wijayantha \\ Loughborough University Department of \\ Chemistry \\ Loughborough University \\ Loughborough, United Kingdom \\ u.wijayantha@lboro.ac.uk
}

\author{
P. S. A. Evans \\ Loughborough University Design School \\ Loughborough University \\ Loughborough, United Kingdom \\ peter.evans@theiet.org
}

\begin{abstract}
In this research the use of micron and nanoparticle metal oxide materials for conductive and dielectric screen printing inks were investigated. Screen printed parallel plate capacitors were fabricated to research the applications of these inks. Conductive, micron-particle indium tin oxide (ITO) screen printing inks were formulated for the conductive plates. A dielectric, nanoparticle aluminium oxide $\left(\mathrm{Al}_{2} \mathrm{O}_{3}\right)$ ink was formulated for the dielectric barrier. Capacitors of varying sizes $\left(1 \mathrm{~cm}^{2}-9 \mathrm{~cm}^{2}\right)$ were printed onto flexible polyethylene terephthalate (PET) sheets. The effect of dielectric layer thickness was investigated to find the optimal fabrication process. Impedance analysis was performed on the capacitors to characterise both the performance of the capacitors and the dielectric ink. Analysis of the capacitors was also performed under flex (up to $30 \%$ strain) to investigate the effect of bending on the electronic properties. The capacitors were found to be highly stable under bending enabling their use in flexible printed electronics applications.
\end{abstract}

Keywords - Passive components, Screen printing, flexible electronics, capacitor, metal oxides

\section{INTRODUCTION}

Capacitors are passive electrical components which store electrical energy between two electrodes within an electric field. There are multiple ways of constructing capacitors, the simplest and most conventional method is the parallel plate capacitor. Parallel-plate capacitors, the focus of this research, are made up of two parallel electrode plates separated by a dielectric barrier and are non-polarised. Electrochemical capacitors are less common and utilize an electrolytic barrier between polarized electrodes using oxidation of the anode as a dielectric barrier. Double layer electrolytic capacitors are also commonly known as 'supercapacitors' and use polarized electrodes with an electrolyte to store electrostatic charge in a Helmholtz double-layer [1].

Capacitors are used as passive components in almost all modern electronic applications. Their uses include signal processing where the energy stored inside a capacitor can be used as memory storage [2]. Other uses include AC/DC signal coupling [3] and signal filtering [4] making their use vital to modern computing.

Traditionally parallel plate capacitors are manufactured using two metallic foil conductive electrodes with a thin film dielectric separating them. However, in the last 20 years advances have been made in low cost, high throughput printed electronics and with capacitors being an integral part of most circuitry, research has been conducted into printed capacitors for flexible printed electronics. One of the earliest works in this field used offset lithography and other roll to roll printing methods with silver inks and polymer dielectric films to produce fully printed capacitors [5-7]. Research then expanded into looking at the properties of high dielectric constant ceramic inks for printed capacitors using both ink-jet and screen printing [8-10].

This work builds upon previous iterations of printed parallel plate capacitors by introducing stable and flexible metal oxide conductive inks and dielectric inks to create a fully screen printed parallel plate ceramic capacitor. These capacitors avoid metallic ink oxidation issues commonly found in nickel and copper while being able to utilize high dielectric constant materials.

\section{MATERIALS AND MethodS}

\section{A. Materials}

Indium Tin Oxide (ITO) $(99.99 \%$ metals basis, Alfa Aesar) powder was used to formulate a conductive metaloxide screen printing ink for printed electrodes. A nitrocellulose (NC) based vehicle donated by Gwent Electronic Materials was used as the base for the ITO ink. Aluminum Oxide ( $<50 \mathrm{~nm}$ nanopowder, Sigma Aldrich) was used to formulate a metal-oxide dielectric ink. This ink used an alkyd resin / high grade paraffin-based vehicle to develop the screen printing ink. The flexible substrate used in this research was clear Melinex ST504 Heat-Stabilized polyethylene terephthalate (PET) and was donated by Dupont Teijin Films. Silver contacts were printed using a Silver screen printing ink (C2131014D3, Gwent Electronic Materials).

\section{B. Capacitor Fabrication}

Indium Tin Oxide $(\sim 50 \Omega / \square)$ electrodes were printed onto PET substrates with varying electrode areas ranging from $1 \mathrm{~cm}^{2}$ to $9 \mathrm{~cm}^{2}$ (Figure. 1a-b) All screen prints were performed using stainless steel screens using $230(75 / 36)$ meshes on a DEK 1202 screen printer. ITO electrodes were cured in a box oven at $105^{\circ} \mathrm{C}$ before having alumina dielectric ink printed on top. The area of dielectric ink was 
greater than the area of electrode ink to prevent short circuits, see Fig. 1. To eliminate pinholes in the dielectric film, multiple printing passes of dielectric were performed, ranging from 1 to 6 passes. The print is once again placed in a box oven at $105^{\circ} \mathrm{C}$ to cure the alumina dielectric ink. A final ITO electrode and silver contacts are printed onto the structure, the capacitor goes through a final curing stage at $105^{\circ} \mathrm{C}$ in a box oven for 5 minutes.

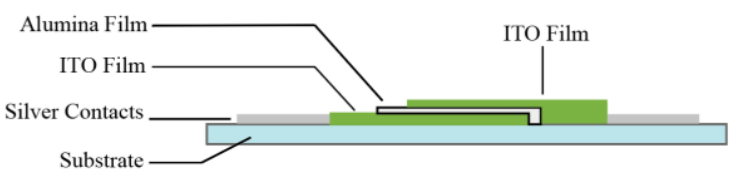

a

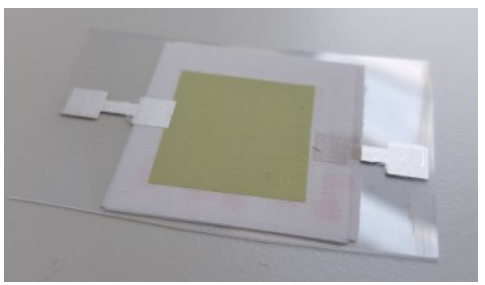

b

Fig. 1. (a) Screen printed capacitor structure, (b) Image of screen printed $2 \mathrm{~cm}^{2}$ capacitor

\section{Measurement Equipment}

Capacitance measurements were taken using a UNI-T digital LCR meter (UT612), these measurements were taken using the LCR meter connected to a PC using the UNI-T digital multimeter software provided. Sheet resistance measurements were taken using a Jandel HM21 four-point probe. Impedance spectroscopy measurements were taken using a Metrohm Autolab Instruments multi-channel potentiostat / galvanostat (PGSTAT12) using Metrohm's Frequency Response Analyzer software (v4.7.900). Data analysis of complex impedance data was performed using Autolab Nova (v2.0). Impedance measurements were taken using 100 measuring steps between $1 \mathrm{MHz}$ and $100 \mathrm{~Hz}$ with an amplitude of $0.01 \mathrm{~V}$. Profilometry measurements were performed on a Talysurf CLI 2000 and data was analyzed in the Talymap Platinum (v5) software package.

\section{RESULTS}

\section{A. Dielectric Layer Thickness and Properties}

An initial study was undertaken into the change in dielectric properties versus the amount of printing passes undertaken. All capacitors which one or two printing passes of dielectric would short. The most likely explanation for this is the presence of pinholes in the printed layer [11]. To create a full coating with no pinholes at least three printing passes of dielectric ink are required. Capacitors with a $2 \mathrm{~cm}^{2}$ area were printed with printing passes of dielectric ink ranging from $3-6$ layers. Profilometry measurements (Figure. 2a) were taken each sample and the average dielectric layer thickness per printing pass (Table. 1).
TABLE I. AVERAGE DIELECTRIC THICKNESS PER PRINTING PASS

\begin{tabular}{|c|c|}
\hline Printing Passes & Average Dielectric Layer Thickness / $\boldsymbol{\mu m}$ \\
\hline 3 & 51.4 \\
\hline 4 & 67.6 \\
\hline 5 & 83.2 \\
\hline 6 & 92.8 \\
\hline
\end{tabular}

Dielectric impedance spectroscopy was performed on the samples (Figure. 2b) showing that three printing passes gives the highest dielectric constant across the spectrum with a dielectric constant of 7.46 at $100 \mathrm{~Hz}$. High purity alumina has been reported to have a dielectric constant of 10.1 at low frequencies [12]. The difference in dielectric constant can be attributed to leftover organics and binders in the dielectric film and a curing temperature much lower than the recrystallisation temperature.
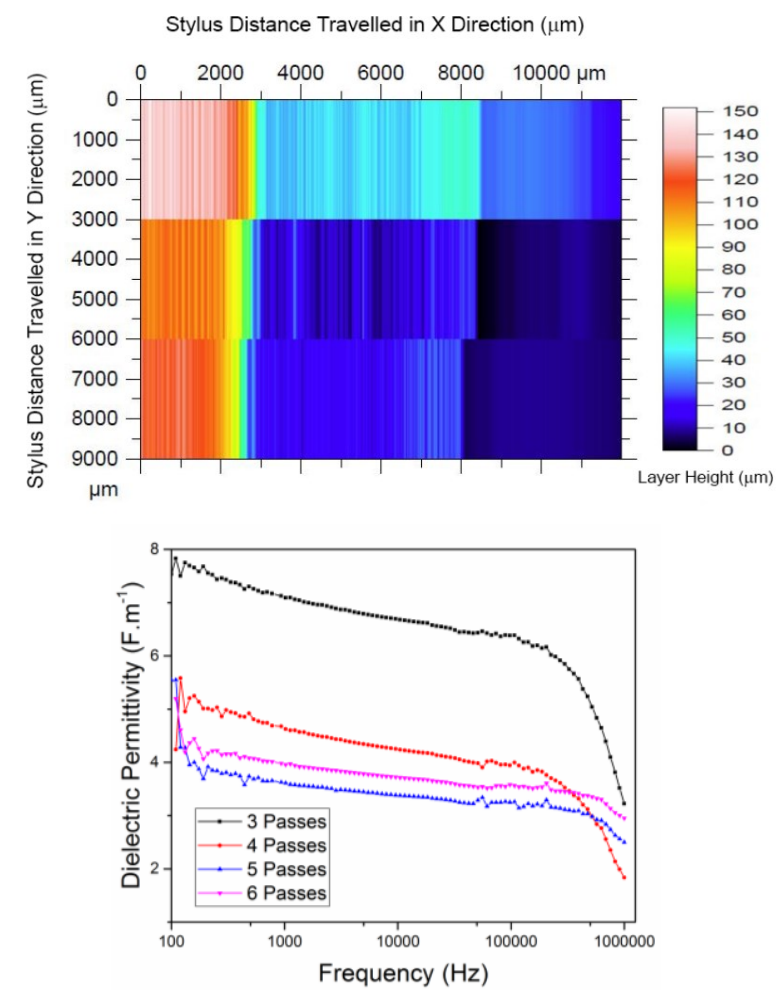

Fig. 2. (a) Stylus profilometry data for a capacitor with 6 dielectric layer printing passes (b) Permittivity vs layer thickness for capacitors

Between four and six printing passes the dielectric constant keeps within a relatively tight range with a dielectric constant between 4 and 5. With an increasing layer thickness in a polycrystalline material the dielectric constant is expected to increase. The decrease in dielectric constant could be due an increase in trapped organics and binders in the thicker film, reducing the polycrystallinity. Curing was also performed after each printing pass meaning organics from lower layers could leech out through the top layers disrupting the polycrystallinity. From this study 3 printing passes of dielectric ink was selected as the optimum amount for all future capacitors in this research.

\section{B. Capacitance Density and tolerances}

Capacitance density (capacitance per unit area) was found to decrease with an increasing electrode area (Figure 3). The biggest decrease was measured between $1 \mathrm{~cm}^{2}$ and $4 \mathrm{~cm}^{2}$. 
Between $4 \mathrm{~cm}^{2}$ and $9 \mathrm{~cm}^{2}$ capacitors a further decrease was measured, however, both electrode area measurements are within the same standard deviation of each other. This suggests after $4 \mathrm{~cm}^{2}$ the capacitance density of the capacitors stabilizes.

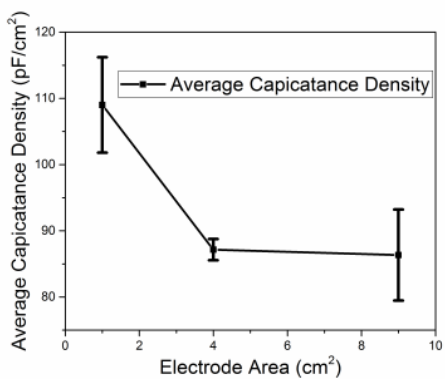

Fig 3. Average capacitance density vs electrode area

The tolerance of the capacitors was measured (as shown in Table 2) with $4 \mathrm{~cm}^{2}$ capacitors having the smallest tolerance window.

TABLE II. TOLERANCES OF CAPACITORS

\begin{tabular}{|c|c|c|}
\hline $\begin{array}{c}\text { Electrode } \\
\text { Area } / \mathbf{c m}^{2}\end{array}$ & Average Cap Density $/ \mathbf{p F} / \mathbf{c m}^{2}$ & Tolerance \\
\hline 1 & 109 & $-5 \% /+7 \%$ \\
\hline 4 & 87.15 & $-1.5 \% /+2 \%$ \\
\hline 9 & 86.34 & $-7.6 \% /+8 \%$ \\
\hline
\end{tabular}

\section{Impedance Analysis}

Impedance analysis was performed on the capacitors between $100 \mathrm{~Hz}$ and $1 \mathrm{MHz}$. As can be seen in figure 4, an increase in electrode area creates a lower overall impedance. The results appear to show a straight line which is expected of capacitors. An ideal capacitor would give a straight line at $90^{\circ}$ in the $\mathrm{Y}$ axis. As no real capacitor has perfect ideal behavior the degree of it's non-ideality can be measured from how close the data is to 90 degrees. With an increasing electrode area, a shift right in the real impedance is shown. As the ESR can be attributed to a cross in the real impedance axis, this suggests an ESR increase with increasing area.

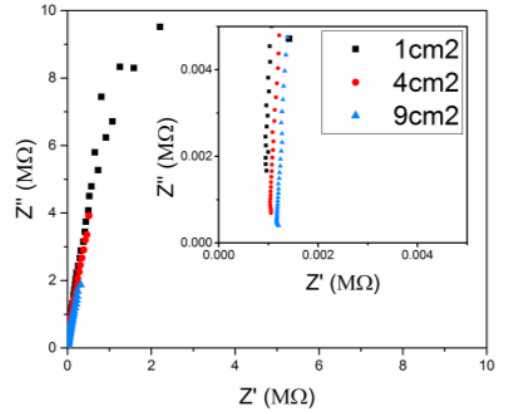

Fig. 4. Impedance analysis data for flexed capacitors

\section{Frequency vs Capacitance and Frequency Response}

With an increasing frequency the ability for the capacitor to react to the AC signal (it's reactance $\mathrm{X}_{\mathrm{C}}$ ) decreases. This decreases the ability of the capacitor to store electric charge in an electric field. Figure 5(a) shows this expected capacitance decrease with frequency increase.
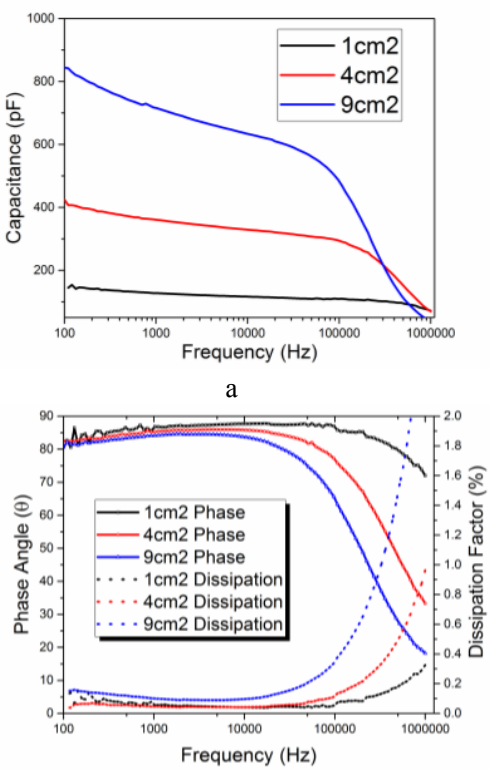

Fig. 5. Frequency spectrum data for (a) capacitance vs frequency and (b) AC signal phase shift vs frequency, and the dissipation factor increase with frequency

The relationship between the phase shift and frequency (Figure 5(b)) correlates with the magnitude of capacitance drop off in Figure 5(a). At a higher capacitance the cutoff frequency is lower and creates a more well defined cutoff point. The dissipation factor and dielectric field loss of the material increases with frequency in figure 5(b), contributing to the decrease in capacitance. Dissipation factors of the capacitors range from 0.05 to $0.2 \%$ up to $90 \mathrm{kHz}$. The $1 \mathrm{~cm}^{2}$ capacitors increase up to $0.2 \%$ at $1 \mathrm{MHz}$, whereas the $4 \mathrm{~cm}^{2}$ increase to $1 \%$ and the $9 \mathrm{~cm}^{2}$ capacitors increase to a $2 \%$ dissipation factor.

\section{E. Flexibility of Capacitors}

Impedance spectroscopy was performed on the printed capacitors under bending. Capacitors were measured before flexing. Samples were then clamped into a strained position with $30 \%$ strain applied. The strain applied was calculated using equation 2 , where the percentage of strain $(\varepsilon)$ is defined as the difference in the initial length of the component $\left(l_{0}\right)$ and the flexed length of the component $\left(l_{1}\right)$ divided by the initial length $\left(l_{0}\right)$. The capacitors were then placed flat and measured for a final time.

$$
\varepsilon=\left(l_{o}-l_{1}\right) / l_{o}
$$

Impedance spectroscopy was performed on the printed capacitors under bending, during bending and after bending as can be seen in Figure. $6(\mathrm{a}-\mathrm{d})$.

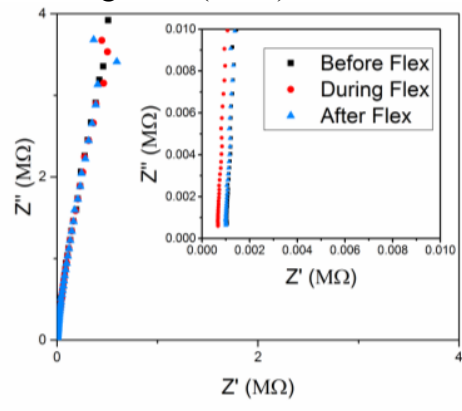




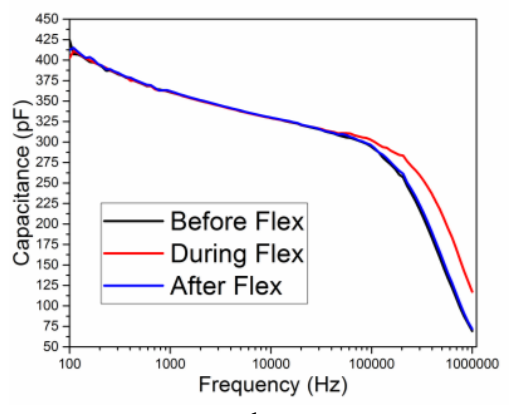

b

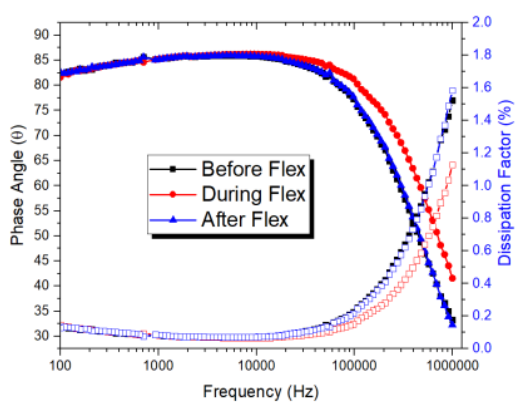

c

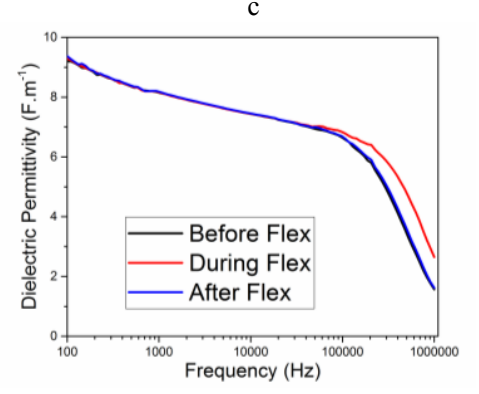

Fig. 7. Electronic analysis of flexed $4 \mathrm{~cm}^{2}$ sample with data showing analysis before, during and after bending for (a) impedance measurements, (b) capacitance vs frequency measurements, (c) phase shift analysis and dissipation factor and (d) dielectric constant vs frequency

The Nyquist plots in figure 6(a) for the pre and post flexed positions are completely overlaid demonstrating minimal hysteresis in the capacitors. The flexed samples showed a shift to the left in the real impedance axis suggesting a lowering of effective series resistance during the bend. The capacitance also increases in the in the high frequency region (as shown in Figure 6(b)) and remains unchanged in the low frequency region. Analysing the bode plot (Figure 6(c)) shows that the phase shift occurs at higher frequencies during bending while once again remaining the same at lower frequencies. The dielectrics ability to store electric energy in the electric field increases at higher frequencies (Figure 6(c-d)) along with a decrease in the dielectric loss factor. This explains why capacitance increases in the higher frequency regions.

\section{CONCLUSIONS AND FUTURE WORK}

Alumina and ITO inks were developed for the printing of all metal oxide capacitors. The capacitors exhibited tolerances between $+/-8 \%$ with dissipation factors below $0.2 \%$ between $100 \mathrm{~Hz}$ and $100 \mathrm{kHz}$ with dissipation factors ranging from 0.4 to $3 \%$ at $1 \mathrm{MHz}$ dependant on electrode area. Capacitors were tested across a frequency spectrum during flexing. The capacitors exhibited a small hysteresis before and after flexing with a greater effect being had in the higher frequencies. Performance did not change during flexing between $100 \mathrm{~Hz}-90 \mathrm{kHz}$ enabling them as highly stable under flex for lower frequency applications such as printed signal filtering and smart packaging. Future research will be conducted into the performance of the capacitors in fully printed filter circuitry.

\section{ACKNOWLEDGMENTS}

The authors greatly appreciate the help of industrial partners. This study was conducted with the help of Professor. Bill MacDonald of Dupont Teijin Films who has supplied the PET films used. The research was funded as part of the EPSRC grant (EP/L017709/1) for research into "Sustainable Manufacturing of Transparent Conducting Oxide (TCO) Inks and Thin Films" - a collaboration between Loughborough University's Design School, the Department of Chemistry, Wolfson School of Mechanical Engineering and Manufacturing and University College London (UCL). The authors acknowledge and appreciate use of metrology facilities within the Loughborough University's School of Mechanical, Electrical and Manufacturing Engineering guided by Jagpal Singh.

\section{REFERENCES}

[1] M. Jayalakshmi and K. Balasubramanian, "Simple Capacitors to Supercapacitors - An Overview," International Journal of Electrochemical Science, pp. 1196 - 1217, 2008.

[2] J. F. Scott, "High-Dielectric Constant Thin Films for Dynamic Random Access Memories (DRAM)," Annual Review of Materials Science, pp. 79-100, 1998.

[3] H. S. Athab and D. D.-C. Lu, "A High-Efficiency AC/DC Convertor with Quasi-Active Power Factor Correction," IEEE Transactions of Power Electronics, pp. 1103 - 1109, 2010.

[4] T. M. Zeeff, T. H. Hubing, T. P. Van Doren and D. Pommerenke, "Analysis of Simple Two-Capacitor Low-Pass Filters," IEEE Transactions on Electromagnetic Compatibility, pp. 595 - 601, 2003.

[5] P. M. Harrey, P. S. A. Evans and D. J. Harrison, "Integrated capacitors for conductive lithographic film circuits," IEEE Transactions on Electronics Packaging Manufacturing, vol. 24, no. 4, pp. 333-338, 2001.

[6] S. Khan, L. Lorenzelli and R. S. Dahiya, "Technologies for Printing Sensors and Electronics Over Large Flexible Substrates: A Review," IEEE Sensors, vol. 15, no. 6, pp. 3164-3185, 2015.

[7] M. Jung, J. Kim, J. Noh, N. Lim and C. Lim, "All-Printed and Roll-toRoll-Printable 13.56-MHz-Operated 1-bit RF Tag on Plastic Foils," IEEE Transactions of Electronic Devices, vol. 57, no. 3, pp. 571-580, 2010.

[8] P.-J. Lin, H.-M. Chang, C.-C. Yuan, Y.-J. Huang, L.-S. Chen, H.-C. $\mathrm{Hsu}$ and $\mathrm{S} . \mathrm{-L}$. Fu, "Fabrication and characterization of passive devices on flexible substrates," in International Conference on Electronic Materials and Packaging, Taipei, 2008.

[9] B. J. Kang, C. K. Lee and J. H. Oh, "All-inkjet-printed electrical components and circuit fabrication on a plastic substrate," Microelectronic Engineering, vol. 97, pp. 251-254, 2012.

[10] B. S. Cook, J. R. Cooper and M. M. Tentzeris, "Multi-Layer RF Capacitors on Flexible Substrates Utilizing Inkjet Printed Dielectric Polymers," IEEE Microwave and Wireless Components Letters, vol. 23, no. 7, pp. 353-355, 2013.

[11] Du Pont Electronics, "Void elimination in screen printed thick film dielectric pastes," European Study Group with Industry (ESGI 29), Oxford, 1996.

[12] J. S. Thorp, M. Akhtaruzzaman and D. Evans, "The dielectric properties of alumina substrates for microelectronic packaging," Journal of Materials Science, vol. 25, no. 9, pp. 4143-4149, 1992 